\title{
Actualización y unificación del derecho privado*
}

\section{Fernando Hinestrosa ${ }^{* *}$}

El que no me reduzca a presentar el saludo de la Universidad y a celebrar la presencia de Ustedes y la realización de este encuentro científico, sino que, como conferencista, emprenda la marcha con lo que pudiera llamar sin pompa una aproximación al presente del derecho privado y un wishful thinking de determinado futuro suyo, se debe a la insistencia amable y generosa del Dr. Saúl Sotomonte, director del Departamento de Derecho Comercial y organizador del certamen. O sea que a él lo llamaré en garantía tan pronto como los participantes me hagan efectiva responsabilidad por las carencias de la exposición.

Como práctica calisténica, permítaseme explicar el título de la ponencia en términos semánticos: ¿por qué "actualización" y no "modernización”?, y ¿por qué "unificación" y no "unidad"? ¿Y por qué en ese orden? Actualizar implica poner las cosas en tiempo presente, se relaciona, por eso mismo, con el ser real y verdadero y, en últimas, significa vivir en la actualidad. Modernizar, remitido en algún diccionario apenas a "dar forma o aspecto moderno a cosas antiguas", no

Conferencia pronunciada en la Universidad Externado de Colombia en el Congreso Internacional de Derecho Comercial, Bogotá, 27 a 29 de septiembre de 1994.

Para citar el artículo: Hinestrosa, F., "Actualización y unificación del derecho privado", Revista de Derecho Privado, Universidad Externado de Colombia, n. ${ }^{\circ} 35$, julio-diciembre 2018, 5-I 7 . Dor: https://doi.org/ro.1860I/or234366.n35.0I

** Rector de la Universidad Externado de Colombia y profesor en ella de Derecho Civil (196320I 2), Bogotá, Colombia.

La Revista de Derecho Privado presenta, a partir del número 24, los trabajos referidos al derecho civil y romano de quien fuera su fundador y constante y decidido animador. La mayoría de los trabajos ya han sido publicados, pero el afán de facilitar su divulgación, en especial entre los estudiantes, nos lleva a volverlos a presentar, seguros no solo de su utilidad, sino también de su permanente actualidad. 
obstante la fascinación del modernismo y de su impacto en la literatura, las artes plásticas, la música, y su proximidad a aquellas actitudes y aptitudes, incita a la polémica entre lo nuevo y lo viejo, tradición e innovación, a la que uno no quisiera sustraerse, pero que fácilmente conduce a la esterilidad del nominalismo. $\mathrm{Y}$, hoy, además, con el riesgo de caer en el conflicto del o con el posmodernismo, "unificación", que no unidad, porque a tiempo que esta da a entender indivisibilidad, conformidad, algo dado, la unificación incita al obrar, a juntar "cosas diferentes o separadas, para que produzcan un mismo efecto o tengan una misma finalidad". En fin, la preocupación inicial y mayor ha de ser la búsqueda de la autenticidad, que exige actualidad y modernidad, inclusive, pensando que como resultado de tal empeño haya de venir, si no espontáneamente, al menos sin tantas dificultades, la unificación. Todo esto, naturalmente, referido al derecho privado.

Derecho privado, derecho de los particulares en sus relaciones como tales entre sí. Regulación de los intereses que tienen y las actividades que adelantan los sujetos individuales o colectivos para la atención de sus deseos, necesidades, por su propia iniciativa. Recortado habitualmente ese campo al ámbito hasta donde alcanza la visión del patrimonio, por cuanto los intereses económicos sobresalen, entre otras razones por lo apremiantes en todo sentido, la sociedad contemporánea ha venido restaurando y revaluando los intereses personales, afectivos, familiares, culturales, recreacionales (prefiero mencionarlos así, en su variedad, a acudir al expediente tan cómodo como insignificante de llamarlos "extra" o "no patrimoniales"), descubriendo nuevas categorías y figuras de ellos, y colocándolos, como bien lo merecen, en el primer plano, así no tengan que ver con la producción de riqueza, o su nexo con el dinero solo se haga presente a la hora de medir el resarcimiento o la compensación debidos a causa de su quebranto, con cuántas vacilaciones y reticencias para fijar su monto.

La persona y la personalidad jurídica, los bienes de la personalidad, la familia y las relaciones directa e indirectamente de familia, los bienes patrimoniales, las relaciones crediticias obligaciones, la autonomía privada, su regulación y la disciplina de los actos de ejercicio suyo más frecuentes y destacados (rectius, contratos), la sucesión por causa de muerte. Hasta aquí un catálogo de las materias del derecho civil, que viene desde la sistematización de los racionalistas y que los códigos y la doctrina han reproducido con ligeras variantes. ¿Que esta distribución y tratamiento de las materias corresponde a una sociedad basada en la primacía de la propiedad privada y, dentro de ella, de la propiedad inmobiliaria? Habría que distinguir lo que es propio de la naturaleza de las cosas, de aquello que evidentemente corresponde a unas determinadas estructuras económicas y formas sociales y "a una visión estática y cerrada de la economía”, vertido, más que en los índices de materias, en su contenido y en la orientación política del ordenamiento.

¿Quién no recuerda en sus estudios de historia y, más en los de historia del derecho, la descripción y la explicación del surgimiento sucesivo de nuevas 
actividades y relaciones con un indefectible tinte de protección y favor de los sujetos pertenecientes a corporaciones, guildas, gremios, clases y, más recientemente, por extensión, a sectores desvalidos o destituidos económica, social, políticamente? Así aparecieron y se han ido desarrollando ramas del derecho, desprendidas, a veces con desgarramiento, del tronco del derecho civil o derecho común: el derecho de los comerciantes -el más antiguo y prepotente-, el de los trabajadores dependientes o trabajadores por antonomasia, el de la familia, el de los menores, el de los indígenas.

El afán de individualizar los caracteres de cada una de esas ramas en una disciplina que responda a sus finalidades económicas, sociales y políticas específicas, y el anhelo de afirmación de sus sostenedores y cultores, contribuyeron a una especie de rebeldía, por encima del autonomismo justificado (complejo de Edipo, dicen algunos despectivamente; de mi parte, no dejo de reprochar a los juristas anclados en el pretérito, de que han sido ejemplo, mas no único, los civilistas tradicionales, el mantenerse rumiando las viejas glorias de su materia, como aristocracia destronada). Independencia que no se redujo al derecho sustancial, sino que avanzó hacia el de procedimiento y llegó hasta establecer jurisdicciones propias, especializadas, estatales y arbitrales. El derecho comercial, como es bien sabido, surgió como necesidad de superar la rigidez y el anquilosamiento del ius civile (agregaría el adjetivo vetus, si no se prestara al cargo de anacronismo) y de elaborar reglas que se acompasaran con las exigencias de celeridad, seguridad y utilidad, propias de la actividad mercantil, y bien puede ufanarse de haber logrado un remozamiento amplio y profundo de las instituciones jurídicas privadas. La explicación política, jurídica y ética del derecho del trabajo es aún más viva e intensa: aquello que vino a degenerar en lugar común de la demagogia: desplazar la figura del arrendamiento de servicios, darle al trabajo del hombre la dignidad que merece y emprender el camino de la tutela efectiva del trabajador, que no puede abandonarse al calor de las invectivas contra las ineficientes y demasías del Estado de bienestar. Así también, más recientemente, emergieron el derecho de familia y el derecho del menor, a fin de privilegiar al grupo familiar (hoy sin calificarlo o descalificarlo por la forma como se constituyó) y de proteger con mayor firmeza y amplitud a sus miembros más débiles: la mujer y el menor. Con una anotación, hoy ya histórica, pero que seguirá valiendo como advertencia: los Estados totalitarios, con la bandera de la defensa de valores y principios radicados en la familia, la niñez, la juventud, y anunciando tutela y protección especiales, quisieron apoderarse de la familia y, por ese conducto, de la conciencia y la libertad de los ciudadanos: de ahí los códigos de derecho de familia, con estatización y suplantación manifiestas, presentados como adelanto. Desenmascarado el propósito y liquidados los totalitarismos, el embeleco del código aparte ha venido cediendo y retorna la tendencia al derecho civil unificado, que sustenta la autonomía de la persona en lo más sagrado, íntimo y personal que puede tener, como es su condición de cónyuge o compañero, de progenitor, de descendiente, 
de pariente, donde no puede ni debe permitir ser suplantado por ningún poder estatal o para-estatal.

Como ocurre en tantos campos, del que el político sirve de paradigma, el ejemplo demostrativo hace carrera, y lo que un milenio ha le ocurrió al derecho civil con el comercial, les sucede ahora a este con sus vástagos, y a las otras ramas con sus respectivos gajos, y con razones de mérito y de oportunidad análogas, solo que esto acontece en una época en que habría que esperar a que la experiencia, la madurez, la universalización de las relaciones permitieran una compaginación razonable y práctica entre la desconcentración y la autonomía de los ordenamientos (especialidad), de una parte, y la indispensable unidad conceptual y de orientación jurídico-política del Estado y, con mayor universalidad, de la comunidad de naciones y del derecho, por la otra.

Nada más engañoso y perverso en este terreno que el juego de la nomenclatura: el creer que, por cuanto el hombre subsiste, la figura actual es la misma de hace cientos o miles de años, o apenas unos cuantos lustros; o que dándole otro nombre a una institución la mentalidad, los hábitos y los vicios cambian como por ensalmo. Esto se ata al fetichismo de la legislación, tan arraigado y estimulado por el sentimentalismo y la demagogia, a la par que por la improvisación y la pereza intelectual. Con la misma se va del aserto de que ya todo está dado (postura hoy insostenible, por lo cual sus partidarios tercian en favor de restaurar el ordenamiento acabado de derogar, "espantados con el cuero del tigre", empleando con argumentos efectistas, como los que circulan ahora con espíritu análogo al de los así llamados "regeneradores" en su día, en favor del orden, la autoridad, el purismo y, ante todo, la antigüedad disfrazada de tradición), se va, digo, al otro extremo: al afán de cambiarlo todo, por cambiar, cuántas veces por mero protagonismo, al improviso, sin percatarse siquiera de que, para avanzar más, en oportunidades hay que remontarse más atrás, como en el caso colombiano con las normas sobre filiación, matrimonio y divorcio, a propósito de las cuales el ideal durante buena parte de este siglo fue el de "“retroceder" hasta la legislación avanzada de los años cincuentas y sesentas del siglo pasado! Y, por contagio de la sociedad de consumo, de las mercancías desechables y los instrumentos rápidamente obsoletos, que autoriza a desentenderse de la calidad de su fabricación, porque a poco ya prestaron su servicio y se pueden reemplazar por otros relucientes, cuántas leyes y decretos, elaborados a la ligera y toscamente, hasta el extremo de que no son pocas las veces en que su vigencia ha tenido que ser pospuesta mientras se corrigen defectos de fábrica, ni escasos los que han tenido que ser recogidos y puestos fuera de circulación por esa o análogas razones.

Unidad del derecho, indispensable de suyo, pero más en un momento histórico en que la especie, y, concretamente, la nación colombiana, hace un replanteamiento de su función, en que siente la urgencia de volver a creer en sí misma 
y en el valor de las instituciones jurídicas y políticas y en el derecho como instrumento, no solo de solución pacífica y equitativa de conflictos, sino de avance hacia la solidaridad y el igualitarismo, esto es, como factor de transformación y progreso. Actitud cuya manifestación más destacada y prestante se encuentra en la expedición de la nueva Carta Política, a la par que en la adopción y vigencia de tratados, convenciones y pactos sobre derechos humanos, y más aún, en el reconocimiento teórico y práctico de la supremacía de estos sobre leyes y constituciones; y, en la cúspide, el imperio de los derechos fundamentales por encima de cualquier norma, inclusive de los propios tratados. Derechos de los que con propiedad se habría de predicar que son ley de leyes.

Pues bien, esta nueva cultura de la dignidad de la persona, de la participación, de la descentralización del poder, de la tolerancia, del pluralismo, de la misión del Estado como guardián interviniente y activo de la vigencia de esos valores, de la solidaridad -distinta de la mera seguridad y aun opuesta a ella-, de la iniciativa y la autonomía privadas, pero en armonía con el interés público y subordinadas a los fines supremos de la comunidad, no puede darse por sentada y establecida ya, con el mero cambio de normas supremas, como tampoco podría aplazarse su vigencia en espera de la expedición de sucesivos ordenamientos de desarrollo y reglamentación de aquellas.

El vigor de los principios de la Constitución es tarea del Estado y de los ciudadanos, juristas y no letrados. A ellos han de someterse las nuevas normas, sentencias y prácticas del derecho, como también las antiguas. Esta y no otra tiene que ser la clave de la recuperación de Colombia como Estado social de derecho, la salida de la anomia que está disolviendo la sociedad civil, en fin, la expresión auténtica de una moral pública, cívica. Unidad del derecho expresada en la primacía de los valores que nutren la nacionalidad, a su vez contenidos en la Constitución y en la doctrina constitucional, resultado de madurez política y no de imposición autoritaria o de la inercia de nostalgias superadas.

Pero, a más de esa razón política, digo ideológica, de unidad, obran otros motivos no exclusivamente de orden práctico, en favor de ella. Me refiero en particular a lo que podría denominar el feudalismo normativo: cuántas baronías, marcas, condados o simplemente feudos. Esto va desde una tendencia que podría considerarse razonable a la especialización, como la que se manifiesta en los derechos bancario, de seguros, bursátil, financiero en general, cooperativo, minero, ecológico, hasta el ánimo de obtener regímenes específicos para determinadas figuras comunes, simplemente por tratarse de determinadas actividades o relaciones, como por ejemplo el régimen de sociedades en materia de servicios públicos, para citar el más reciente de los casos. Lo cual conduce a una diversidad enorme de regímenes del todo justificada e insoportable: para cada actividad o para cada sector un estatuto propio, distinto, unas competencias exclusivas, con su trámite aparte, hasta su lenguaje críptico. Procuro no herir susceptibilidades, pero advierto que, al paso que vamos, resultaremos con tantos ordenamientos, 
superintendencias, autoridades administrativas y judiciales, cámaras, colegios y registros públicos -que son privados aun desde antes de la onda de la privatización- cuantos gremios y cofradías se instauren, con sacerdotes especializados y los correspondientes privilegios. $\mathrm{Y}$ aquí nuevamente hago el comentario: por culpa no totalmente achacable a los barones y su aparato feudalizante, pues cuota alta de la responsabilidad incumbe a los establecimientos cristalizados o anquilosados, que difícilmente dan cabida a nuevas expresiones sentidas del derecho.

Y aquí, una cita, para mí oportuna, del brillante jurista Piero Perlingieri:

Para el civilista se abre un programa vasto y sugestivo de investigación que se proponga la actuación de objetivos calificados: identificar un sistema de derecho civil lo más armonizado posible con los principios fundamentales y en especial con las necesidades existenciales de la persona; redefinir, entonces, el fundamento y la extensión de las instituciones jurídicas y especialmente de las civilistas, subrayando sus aspectos funcionales en un intento de revitalizar las normatividades singulares a la luz de un juicio renovado; verificar y adecuar las técnicas y las nociones tradicionales (de la situación subjetiva a la relación jurídica, de la capacidad de obrar a la legitimación, etc.), en un esfuerzo de modernización del instrumental y, concretamente, de la teoría de la interpretación.

Muchas de las pesquisas adelantadas en esta dirección muestran que la vía trazada es fecunda en resultados interesantes destinados en su conjunto a darle una nueva imagen al derecho civil, contribuyendo a la fundación del derecho civil constitucional. $Y$ ese es también el camino por recorrer, reaccionando contra el fraccionamiento del saber jurídico, contra la insidiosa y excesiva división del derecho en ramas y especializaciones que, de llegar a prevalecer, convertirán al jurista, encerrado en su microsistema, en un especialista, que si bien está dotado de refinados instrumentos técnicos sectoriales, resulta acrítico, insensible ante el proyecto complejo de la sociedad, incluso cuando éste, vertido en la ley máxima del Estado, se sitúa claramente en contradicción con grupos de poder o de presión ${ }^{\mathrm{I}}$.

Actualización del derecho privado, inquietud que comienza por replantear su concepto, campo vital y linderos de este. ¿Hay un derecho privado? ¿Cuál es su radio de acción? ¿Cuáles sus relaciones con otras ramas, ante todo las más afines? Las expresiones usuales de "publicización del derecho privado" y "privatización [¿“"civilización”?]” del derecho público han de ceder el paso a una visión más directa y comprometida del mundo del derecho, que tenga en cuenta la integración plena del derecho constitucional, a la vez que la iniciativa y la competencia como leyes inderogables de la vida social, atendibles por el Estado en obsequio 
de su mayor eficiencia y de un mejor cumplimiento de sus fines primordiales. Un derecho privado que reconozca su dualidad patrimonial y personal y atienda a ambas clases de intereses, sin olvidar la jerarquía de los valores en juego.

La economía de hoy, la entronización definitiva y universal de los medios electrónicos, la "globalización" de todo hace patente el contraste, no solo entre las relaciones de la periferia, el mercado aldeano, y la economía de las metrópolis -pero también de los sectores más desarrollados del Tercer Mundo-, sino entre la concepción, los criterios y pautas de los códigos, y la exigencia de las nuevas actividades o, simplemente, las propias del ritmo y los apremios presentes de las instituciones y actividades tradicionales.

¿A qué distancia se encuentra el tráfico jurídico de hoy, la visión y el andamiaje del código civil, o sin ir tan lejos, del código de comercio, en cuántos aspectos nacido viejo? Perdóneseme la comparación: siendo innegable el avance de pasar del código decimonónico del estado de Panamá, venido también de Chile, a un código moderno, que no actual -pues se ignoró la doctrina y la jurisprudencia italianas críticas y correctoras del texto de I942-, en cuántos aspectos diera la impresión de haberse adquirido un modelo de segunda mano.

En materia propiamente civil, comenzando por las personas: ¿qué decir del término legal mínimo de duración del embarazo, o de la noción y regulación del domicilio?, ¿se podrá seguir hablando de "potestad" y de "patria"? Eso no existe más hoy, aun en nuestra sociedad autoritaria, como lo dispone el código, a la representación legal y a la administración y usufructo de los bienes del hijo, en vez de al poder-deber de crianza, educación y orientación de él. ¿Cómo ha de ser tratada la sociedad: como contrato o como persona?

La propiedad mueble, la propiedad intelectual, habrán de continuar siendo tratadas marginalmente. ¿Y qué decir, en general, del régimen de los bienes y de sus intercambios? A este propósito no resisto el deseo de transcribir un pasaje bien ilustrativo de Luminoso:

La civilística contemporánea, remitida precisamente al instrumental conceptual legado por la jurisprudencia romana y luego por la glosa, elabora sus construcciones partiendo del postulado de que, al considerar los bienes desde el punto de vista del influjo del tiempo sobre ellos y de su uso, son concebibles tan sólo dos categorías: las cosas inconsumibles (susceptibles de utilización repetida y, por ello, tendencialmente duraderas, cuando no "eternas") y las cosas consumibles, susceptibles de un acto único de empleo, con el cual desaparecerían en sentido físico o, según el caso, apenas económico. [...] Sobre estas bases se apoya también la moderna teoría jurídica de los intercambios. Ella nos propone, sustancialmente, dos solas formas: cambio de cosa (o sea de su valor capital) por un precio; cambio de goce de la cosa (o sea su valor de uso) por precio. La primera 
especie (p. ej., venta, permuta, suministro) se configura de ordinario como cambio instantáneo (que comporta un traspaso de la titularidad del bien) en donde la contraprestación es el precio del valor capital de la cosa cambiada (consumible o no consumible); la segunda especie (p. ej., arrendamiento, arrendamiento de cosas fructíferas, enfiteusis) es vista como un cambio que se proyecta en el tiempo (que implica la atribución del goce del bien), en donde la contraprestación representa el precio del valor de uso de la cosa (no consumible) cambiada y esta conserva tendencialmente inalterado su valor capital durante el desarrollo del contrato. Como se indicaba atrás, figuras tradicionales de bienes y de intercambios resultan insuficientes para cubrir integro el espectro de las necesidades y de las exigencias planteadas por las estructuras socio-económicas actuales. De ahí que la configuración de operaciones de contenidos económicos innovadores, como aquellas que comúnmente se remiten al leasing (en las distintas formas) denuncie la urgencia de introducir al equipaje conceptual del jurista otras categorías de bienes (de bienes e intercambio) que le permitan resolver convenientemente los complejos problemas de calificación y disciplina que fraccionan fuertemente tanto la doctrina como la jurisprudencia ${ }^{2}$.

La disciplina del contrato es mucho lo que ha variado. La mejor doctrina debate acerca de si debe hablarse de autonomía privada, o apenas de iniciativa privada, en tanto que entre nosotros se sigue hablando de la autonomía de la voluntad, apegados al dogma, que ahora se quiere reforzar bajo los auspicios de la apertura económica y el imperio de las leyes del mercado, y exorcizando la intervención del Estado.

La verdad es que -dice Enzo Roppo- las reglas en materia de contratos de los códigos civiles decimonónicos aparecían en buena medida ligadas a la visión estática y cerrada de la economía, a una concepción del proceso económico que privilegiaba el aspecto del goce de la riqueza antes que el de su circulación y multiplicación; que, en suma, reflejaban un estadio de desarrollo pre-industrial. Con la evolución y los progresos de la economía capitalista se manifestaron en sectores del mercado cada vez más numerosos exigencias de dinamización de los intercambios y de las relaciones, que aquellas reglas no estaban en condiciones de satisfacer; de ahí la necesidad de un conjunto de normas a propósito, que, refiriéndose a las relaciones contractuales más directamente atinentes a la esfera de la producción y de los intercambios económicos, y en particular a aquellas entre empresarios y consumidores, las disciplinaran conforme a esas exigencias.

2 "La locazione finanziaria", Atti del Convegno internazionale, Cagliari, ottobre i987, Padova, Cedam, I $76 \mathrm{~s}$. 
La supresión de la duplicidad de ordenamientos y su absorción en un régimen uniforme de las obligaciones y los contratos constituyen una respuesta específica a las exigencias de un estadio más avanzado de la evolución capitalista. Un estadio en el que ya no parece posible distinguir sectores en donde prevalece la economía estática y atrasada (regulada por la normatividad tradicional de las "relaciones civiles") y sectores aislados de economía dinámica, caracterizada por el flujo creciente de la producción y los intercambios (a que se dedica la disciplina más avanzada y moderna de las "relaciones comerciales"), porque el desarrollo técnico-científico y el advenimiento de la producción, de la distribución y del consumo masivo han determinado una dinamización general de la economía y la extensión del mercado para satisfacer exigencias que antes se circunscribían a algunos sectores limitados. La celeridad y la seguridad de la circulación de los bienes son hoy una necesidad de íntegro el sistema económico. De ahí que las relaciones contractuales hayan de sujetarse a una disciplina unificada 3 .

A los comercialistas que se desentienden del código civil y aspiran a que todos los actos y contratos estén regidos por el código de comercio, aduciendo la "modernidad" de este y su mayor cubrimiento de figuras, no les falta razón, comoquiera que el abanico de materias y su disciplina corresponden allá a una economía, a unas relaciones y a una concepción del mundo diferentes y ya superadas. Cosa distinta es que la jurisprudencia haya venido actualizando - a veces con motivos espasmódicos- aquellas instituciones y que, en su tiempo, les hubiera insuflado el espíritu solidarista y la modernidad de la actitud de la mitad del siglo xx, que penetró al mundo y a Colombia, a lo menos formalmente. Ahora se espera un empujón en el mismo sentido, auspiciado y exigido por la nueva Constitución Política.

Y es que si la doctrina y la jurisprudencia no se actualizan, la necesidad será satisfecha por otras vías, el vacío lo llenarán leyes, decretos, resoluciones, circulares. Peligro real este, al que contribuye, a más de esos auspicios, una larga y abominable práctica de legislación palaciega, que hace recordar al Bajo Imperio -solo que en este había aún juristas de nota al servicio del dominus-; me refiero al estado de sitio que sin solución de continuidad cohonestó el uso y el abuso del artículo i 2 I de la Constitución entre i 948 y i 968, al que se sumó el expediente de las facultades extraordinarias, con traslapo primero y luego en sustitución, quizá de mayor virulencia por su apariencia de legitimidad. Así, a más de incurrir en la normatividad a puerta cerrada, tan proclive a la intriga y el favoritismo, se ha caído en la impulsividad, el capricho y el descuido, hasta en el propio lenguaje. Y aquí no resisto la tentación de hacer mofa de la redacción de artículos interminables, con idiotismos ordinarios y la inclusión del "parágrafo" y el "de que trata" para todo, mal gusto apenas comparable a la numeración "a la 
americana" del I.I.I, I.I.2, I.2.I, 2.I.I, que da la impresión de estar concebidos para párvulos, desprovistos de atención y agilidad en la lectura, que a falta de esas muletas perderían el hilo.

Hablando de actualización, dos notas complementarias: es enorme el número de leyes y decretos extraordinarios reformatorios del código civil, así como es abultado el volumen de materias comerciales reguladas por leyes, decretos, resoluciones y normas "capilares" dispersas, lo que muestra que el espíritu díscolo de este derecho se mantiene y acrecienta, y que la vetustez no es dolencia del solo código civil.

$\mathrm{Al}$ pasar revista a la disciplina del contrato en general y de las figuras contractuales en singular en el código civil, se hace patente que aquellas reglas y el propio catálogo se remiten a unas economía y cultura decimonónicas; mientras que el de comercio habría llegado a la mitad del novecientos. Con ello no estoy abogando por la "institucionalización" de figuras aún no destacadas, a las que los códigos en general no les han dado todavía recibimiento, esto es, tipicidad legal, en espera de su decantación y consolidación, como tantas con nombre en inglés: leasing, factoring, engineering, venture capital, franchising, time share, y otras que designan nuevas formas de garantía del crédito, o cuántas más familiares: carta de crédito, tarjeta de crédito, etc. Pienso en la modernización de la postura ideológica y del criterio jurídico; en el reconocimiento de que el derecho privado es estimulante, propulsor, y no represivo, y de que los particulares bien pueden utilizar figuras por fuera del catálogo legal y aun del social, y el juez ha de aceptar estas disposiciones en cuanto tengan relevancia social, despojando de su habitual nosofobia; en la efectividad de las cláusulas generales de exigencia de la buena fe activa, la proscripción del abuso del derecho y el fraude, con contenido cuya especificidad ha de confiarse al juicio prudente del fallador; en fin, en la universalidad y la agilidad del desempeño del profesional del derecho que permitan la inserción de Colombia en el concierto mundial de la contratación, sin tener que someterse a la casuística del common law con el criterio de que las partes solo tienen los derechos y las obligaciones escritas en el texto, en el que se agotaría el contenido negocial.

Bien sabemos y padecemos la duplicidad de ordenamientos de derecho privado: un código civil de estirpe francesa, el chileno de I855 con multitud retoques, remiendos y adiciones; uno de comercio de I97I, en buena medida transcripción del texto del código civil italiano de i942, que rige paralelamente, con un buen número de normas especiales, unas pocas anteriores, las más posteriores a su vigencia. Código de comercio cuya vocación absorbente es avasalladora, y cuya predilección y favor por el gremio es palmaria (¿cómo no recordar, entonces, la apuntación de Vivante?: "el comercio, especialmente el gran comercio, ha venido creando un derecho para proteger sus propios intereses, y constriñe a todos los ciudadanos que contratan con los comerciantes a sufrir una ley hecha en favor de esa clase”). Así, en la práctica absorbió íntegra la materia 
de sociedades; mantuvo y reforzó la "comercialidad" de todos los denominados "títulos-valores", comenzando por el cheque, y de la oferta; reprodujo con ánimo de expropiación el régimen de quiebras y concordatos del inmediatamente anterior código de procedimiento civil; volvió comerciales hasta los contratos de hospedaje y de edición; reprodujo innecesariamente normas del código civil, con otro lenguaje, e introdujo normas generales innecesariamente contrapuestas a las de aquel, y reguló íntegramente los mismos contratos con régimen antagónico, todo en términos propicios a incertidumbre e inseguridad, tanto más abundantes cuanto más vasto y proclive a la ampliación ha resultado el radio de acción suyo. Y aquí unos cuantos ejemplos sobresalientes: la definición de contrato, el régimen del pacto de arras y de la cláusula penal, la imputación del pago, el régimen de intereses, la cesión de contrato, el régimen de nulidades, la llamada "ineficacia" sui generis, la tradición de bienes sujetos a registro, los riesgos de la cosa vendida, la reserva del dominio.

La pregunta que salta al rompe de manera apremiante es elemental: ¿podrá la sociedad colombiana, la de los ciudadanos ordinarios, la de los comerciantes, la de profesionales del derecho, inclusive, la administración pública, ahora más próxima y ceñida al derecho privado en lo que respecta a los contratos estatales, seguir soportando la inactualidad y la dualidad y contradicción de los dos ordenamientos de derecho privado? La respuesta negativa es clamorosa, con el agravante de que tal situación, que bien pudiera calificarse de caótica y extravagante, no es remediable por medio de los retoques e impulsos de la doctrina o del derecho pretoriano jurisprudencial. Veintitrés años llevamos ya de esta anomalía, sin que hasta el presente las voces y propósitos de enmienda hayan sido atendidos. Nos hacemos lenguas de la indisciplina e hiperestesia del colombiano, sin embargo es patente su pasividad y resignación, cuando no el escapismo que adopta frente a las molestias e incomodidades grandes y pequeñas de la vida ordinaria.

¿Quién le pone el cascabel al gato? Ciertamente hay que señalar algunos hitos importantes, independientemente del juicio de valor que cada cual emita al respecto: el proyecto de código de derecho privado de Arturo Valencia Zea, publicado en i 980 , el proyecto de código civil de la comisión integrada por él, José Alejandro Bonivento y Pedro Lafont Pianetta, de I985, y más recientemente y con varios motivos de inconformidad el proyecto de reforma del libro segundo, sobre sociedades. Indico aparte el proyecto de reforma del régimen de quiebras, concordatos y liquidaciones administrativas, por lo mismo que, en mi sentir, la materia que con mayor amplitud podría denominarse "crisis de la empresa", y que ha sido objeto de reformas continuas y demanda con urgencia revisión, pertenece al derecho de procedimiento: administrativo o judicial, pero siempre procesal.

Contra lo que se creyera o deseara, vivimos una época de nuevos códigos civiles -por lo general unificados-, no solo en el Tercer Mundo, sino en especial en el primero. No menciono en este orden de ideas a los países de Europa 
central y oriental, que hubieron de expedir rápidamente códigos para restaurar el derecho civil, ni los estatutos de los contratos económicos y de los contratos económicos internacionales de la República Popular China (I98I-I993), dado su ámbito específico y restringido; cito en América los códigos civiles de Perú (1984), Paraguay (1987) y Quebec, en Canadá (1994-1995), a más de la Ley I 7.7 I I argentina de 1968 y los tres proyectos recientes de reforma del código civil, y en Europa, los códigos civiles de Portugal y de los Países Bajos, modelos de modernidad. Bien podría entonces evocarse la famosa polémica entre Savigny y Thibaut, para afirmar la "vocación de nuestro [fin de] siglo", no digo "para el derecho", como se ha solido traducir el título del famoso libro del primero, sino "para la codificación".

Otra cosa es que la labor de codificación sea ardua, lenta y haya de ser pluralista, debatida y decantada. El símil es vistoso y útil: nadie de suyo busca ni ama la cirugía para sí mismo, lo que no quita la indispensabilidad de esa técnica; al quirófano solo se llega una vez agotados y fallidos los esfuerzos de la terapia; la intervención no se puede improvisar, salvas las operaciones de urgencia; el equipo que opera ha de estar integrado por profesionales de la mayor competencia, escogidos con esmero exquisito, y el buen suceso presupone la coordinación y armonía de todos sus integrantes.

En Francia, por ejemplo, han venido trabajando permanentemente, desde hace años, comisiones de reforma de los códigos, entre ellos el civil, que al cabo de mucho esfuerzo, deliberación y consenso entregan resultados concretos a los poderes públicos, y que estos a la postre convierten en normas. $Y$ un ejemplo nacional, infortunadamente de esfuerzos inconclusos o, mejor, interrumpido por pérdida de voluntad política: el de la Comisión de Reforma del Código Civil de 1939, en época de un espíritu colosal de aggiornamento de la nación entera, como fue la segunda República Liberal, y más el período de la "Revolución en marcha": en orden cronológico cito como hitos fundamentales la Ley 28 de I932, la reforma constitucional de 1936 , las leyes 45, 50, 63 y 200 de I 936 , la jurisprudencia de la Sala de Casación Civil de la nueva Corte Suprema de I935. Y destaco la importancia de tal ejemplo, porque fue un propósito verdaderamente nacional, de actualización del Estado y del derecho, un empeño conjunto del Congreso constituyente y del legislador ordinario, del ejecutivo como colegislador y reglamentador, y de la jurisdicción, a más de las universidades y del foro.

Y, ahora, déjenme soñar: dentro del espíritu de renovación y de recuperación del derecho y las instituciones que nos anima e impulsa, creo -¿quiero creer?que se está incubando un movimiento similar. En los cambios de milenio, y estamos próximos a uno, las gentes se agitan, la superstición se expande y aumenta la creencia en acontecimientos extraordinarios y supranaturales, se esperan y hasta ven milagros: ¿por qué, entonces, no empeñarnos todos en hacer el nuestro: un derecho privado actualizado, nuestro y unificado? $\mathrm{Y}$ al decir nuestro, no me refiero solo a Colombia. Pertenecemos a una comunidad cultural más amplia, 
somos latinoamericanos y nuestro futuro está cifrado en serlo con mayor amplitud y profundidad. Un código civil común o, cuando menos, unos principios o bases generales comunes, no es una quimera: la similitud de los códigos chileno, colombiano, ecuatoriano y uruguayo, y aun del argentino, es comparable a la similitud de los códigos mexicano y venezolano, y a la de los códigos peruano y paraguayo. Por lo demás, si no procedemos a tales aproximación y comunidad, quedaremos expuestos a perder nuestra identidad jurídica continental y a una aculturación forzada, por no decir a una colonización que ya se vislumbra. 